\title{
The prevalence of anal sphincter defects in faecal incontinence: a prospective endosonic study
}

\author{
K I Deen, D Kumar, J G Williams, J Olliff, M R B Keighley
}

\begin{abstract}
Forty six patients (median age 61 years; 42 women) with faecal incontinence and 16 age and sex matched controls undergoing a restorative proctocolectomy were assessed by clinical examination, anorectal physiology, and anal endosonography. Forty patients $(87 \%)$ with faecal incontinence had a sphincter defect demonstrated on anal endosonography (31 external and 21 internal anal sphincter defects). The commonest cause of faecal incontinence was obstetric trauma. This occurred in 35 women, 30 of whom exhibited a morphological defect in the anorectal sphincter complex. In 22 of these patients with a history of a perineal tear or episiotomy, $21(95 \%)$ had a sphincter defect. Sphincter defects were commonly located at the level of the midanal canal.
\end{abstract}

(Gut 1993; 34: 685-688)

Defects of the anorectal sphincters are a common cause of faecal incontinence either alone or in combination with pelvic floor neuropathy. ${ }^{12}$ Previous reports on the prevalence of sphincter injury in faecal incontinence have used digital assessment, conventional manometry, and electromyographic sphincter mapping. ${ }^{35}$ We believe that with these methods sphincter defects have been underdiagnosed. This may, in part, be explained by the limitations of digital examination and anorectal manometry to localise such defects, poor patient compliance with electromyographic sphincter mapping, and the unreliability of electromyography in the presence of scar tissue. ${ }^{5}$ Furthermore, electromyography is limited to indentifying defects in the subcutaneous or superficial external anal sphincter only and cannot always localise defects in the deeper component of this muscle. ${ }^{6}$

Anal endosonography is a new technique capable of imaging the external and internal anal sphincters with a high degree of accuracy. ${ }^{7}$ As well as being capable of locating defects in the entire sphincter complex it is quick, easy to perform, and well tolerated by the patient. ${ }^{8}$

The purpose of this study was to assess the prevalence of endosonic anal sphincter defects in patients with faecal incontinence and to correlate morphological defects with anorectal manometry.

\section{Subjects and methods}

\section{PATIENTS}

Forty six patients (42 women, 4 men) aged between 23 and 83 years (median 61 years) with faecal incontinence of three months to 96 months (median 30 months) were assessed by clinical history, anorectal physiology, and anal endosonography. Thirty five patients gave a history of obstetric trauma as the only predisposing factor responsible for faecal incontinence. These patients had had between one and eight vaginal deliveries (median 3) and all had had difficult or prolonged labours which lasted over 36 hours or where the patient was aware of bearing down for a considerable period of time, where there was cephalopelvic disproportion, or where the mother could describe difficulties with parturition such as deep transverse arrest or the application of high forceps. Incontinence was associated with a longstanding rectal prolapse in three patients. Iatrogenic sphincter injury was responsible for five cases and accidental trauma of the sphincter for three others (Table I).

\section{SEVERITY OF FAECAL INCONTINENCE}

Thirty three of 35 patients with an obstetric cause for their symptoms experienced incontinence to flatus and faeces requiring a pad and suffered from more than three accidents a week. The two other patients in this group had incontinence to flatus associated with episodes of faecal leakage immediately after defecation only but were completely continent to solid stool and did not wear a pad. In the rectal prolapse group, all three patients experienced incontinence to flatus, liquid and solid stool and wore pads to counteract faecal leakage. In the group of patients with incontinence from iatrogenic or accidental causes, all but one were incontinent of flatus and liquid and solid stool, and required a pad, and one patient in whom the external anal sphincter was inadvertently divided during a lateral sphincterotomy suffered from incontinence to flatus and urgency with incontinence to liquid stool only.

\section{CONTROLS}

Sixteen age and sex matched patients with ulcerative colitis undergoing a restorative proctocolectomy were carefully chosen to serve as controls because they were considered to have a normal anal sphincter complex. None of these

TABLE I Causes of faecal incontinence

\begin{tabular}{lc}
\hline Causes & No of patients \\
\hline Obstetric & 35 \\
Rectal prolapse & 3 \\
Road traffic accident & 3 \\
Iatrogenic: & 1 \\
External sphincterotomy & 2 \\
Fistula surgery & 1 \\
Drainage of ischiorectal abscess & 1 \\
Dilatation of the anus & \\
\hline
\end{tabular}


Figure 1: Anterior external sphincter defect (extent marked by arrows) in a 33 year old woman who had sustained a perineal tear and on examination had a thin septum dividing the vagina from the anorectum. The extensive defect in the external anal sphincter was confirmed at operation.

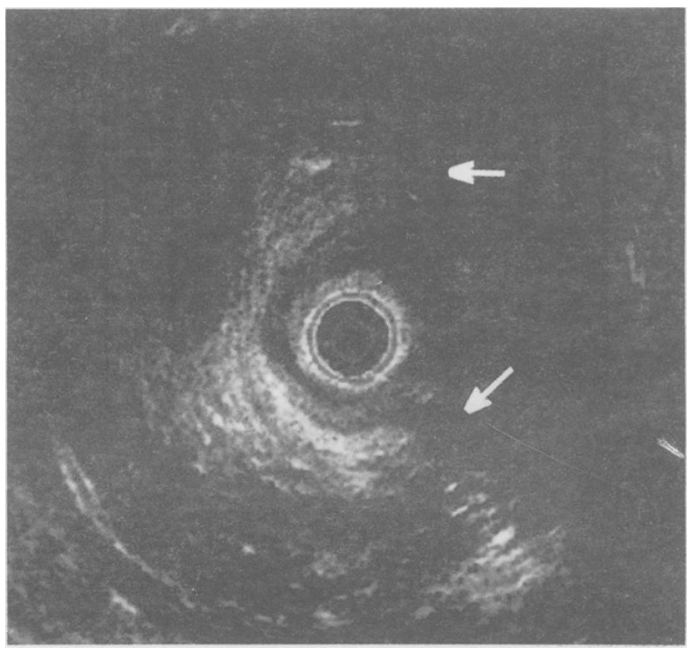

patients gave a previous history of perianal disease such as fissure, haemorrhoids, or sepsis. Although all of them had experienced varying degrees of urgency and tenesmus arising from rectal mucosal involvement, none had experienced episodes of faecal incontinence. All subjects in the control group had macroscopically normal anal mucosa at proctoscopy.

\section{ANAL ENDOSONOGRAPHY}

This was performed with a Bruel and Kjaer (Bruel and Kjaer, Harrow, UK) ultrasound scanner (1846) and a $7 \mathrm{mHz}$ rotary transducer enclosed within a $1.7 \mathrm{~mm}$ sonolucent plastic cone filled with water to maintain acoustic contact. All patients were examined in the left lateral position, and images were obtained at the upper, mid and lower anal canal levels. A hard copy of each image was obtained with a thermal printer and stored for later analysis. Images were orientated when scanning in the left lateral position as previously described.

Defects of the external and sphincter were defined as hypoechoic areas relative to the mixed echo of the rest of the muscle that was either wedge shaped or a more extensive hypoechoic defect of this muscle (Fig 1) in the mid and lower anal canal. This appearance in the upper anal canal was not considered to be an external anal sphincter defect in the presence of a normal

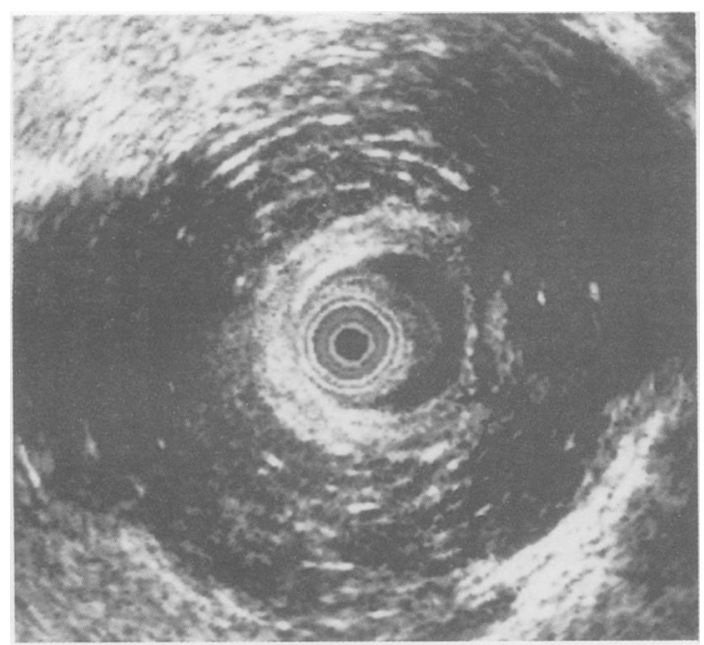

anterior sphincter echo seen along the rest of the anal canal. Posterior areas of hypoechogenicity in the external anal sphincter were defined as defects of the sphincter only when such areas were electrically silent with electromyography or when such defects were confirmed at operation because reflections from the coccyx and anococcygeal raphe could give a similar appearance in healthy subjects. ${ }^{7}$ Similarly a defect of the iniernal anal sphincter was identified as a clear gap in the hypoechoic ring representing this muscle (Fig 2).

\section{ANORECTAL MANOMETRY}

Anal manometry was performed with a closed water filled balloon system attached to a transducer and heat sensitive pen recorder as described previously. ${ }^{9}$ Maximum resting pressure was the baseline pressure recording at rest at each site and maximum squeeze pressure at each recorded site was considered to be the maximum pressure recorded on voluntary contraction of the external anal sphincter.

\section{SPHINCTER NEUROPATHY}

Neuropathic changes in the external anal sphincter and puborectalis muscles were detected with the use of concentric needle electromyography. This was performed with a $0.64 \mathrm{~mm}$ diameter, $77 \mathrm{~mm}$ long needle (Teka, Pleasantville, New York) attached to a preamplifier and oscilloscope with a pen recorder (Medelec UK Ltd). The low and high pass filters were set at $20 \mathrm{~Hz}$ and $10 \mathrm{KHz}$ respectively. Electrical activity in the sphincters was recorded at rest and during voluntary contraction. With a trigger and $10 \mathrm{~ms}$ delay, motor units were analysed for number of sweep phases and duration. Poor recruitment of electrical activity on contraction, multiphasic potentials ( $>4$ phases), and a prolonged duration of motor units $(>7 \mathrm{~ms})^{10}$ were the criteria used for diagnosing sphincter neuropathy. Twenty motor units from different sites were analysed. A neuropathy was diagnosed if more than one half of these individual motor units were multiphasic or prolonged.

\section{STATISTICAL ANALYSIS}

Maximum resting and squeeze pressures between patients and control subjects were compared with the non-parametric Wilcoxon rank sum test.

\section{Results}

SITE AND TYPE OF DEFECT

Forty of $46(87 \%)$ patients had a sphincter defect. Thirty one patients $(67 \%)$ were found to have external and twenty one $(46 \%)$, internal defects (Table II). Of the 35 patients with a positive obstetric history, $30(86 \%)$ had a morphological defect in the anorectal sphincter complex. Twenty patients (57\%) had a sphincter defect in combination with a neuropathic pelvic floor and external anal sphincter, 10 patients $(29 \%)$ had a sphincter defect alone, and five patients (14\%) 
had evidence of pelvic floor and sphincter neuropathy as the sole cause of incontinence (Table III).

\section{PERINEAL TEAR AND EPISIOTOMY}

Twenty three of the patients with obstetric trauma gave a history of having had a perineal tear $(n=8)$ or episiotomy $(n=15)$, one sustaining a tear in spite of an episiotomy at the time of delivery. Each patient had had between one and four episiotomies (median 2). In this subgroup of patients, 16 exhibited a defect of the anterior external anal sphincter and 12 a defect of the internal anal sphincter (eight anterior, four posterior). Six patients were found to have a combined sphincter defect. Hence $95 \%$ of those with a distinct history of a perineal tear or episiotomy had a defective sphincter complex. One patient with a history of two previous episiotomies was found to have entirely normal morphology of the sphincter on endosonography (Table IV).

\section{LEVEL OF DEFECT}

Anal endosonography revealed that $58 \%(18 / 31)$ of defects of the external anal sphincter were mainly at the level of mid-anal canal corresponding to damage in the superficial and deep components of the external sphincter whereas the subcutaneous component in the lower anal canal was the main area of damage in $42 \%(13 / 31)$ of patients. Similarly, most defects of the internal anal sphincter $(76 \% ; 16 / 21)$ were identified in the mid and upper anal canal. The internal sphincter was absent in the lowermost part of the anal canal both in patients and controls (Table V). Interpretation of anterior external sphincter defects in the upper anal canal from anal endosonography alone may provide inaccurate information. Control subjects also exhibited an apparent anterior deficiency of mixed echogenic external sphincter at this level. The most likely explanation for this is the anatomical arrangement of the

TABLE II Distribution of sphincter defects

\begin{tabular}{lr}
\hline Distribution & $N o(\%)$ \\
\hline External sphincter & $19(41)$ \\
Internal sphincter & $9(20)$ \\
Combined & $12(26)$ \\
None & $6(13$ \\
\hline
\end{tabular}

TABLE III Obstetric causes of faecal incontinence

\begin{tabular}{lr}
\hline Causes & $N o(\%)$ \\
\hline Sphincter defect & $10(29)$ \\
Sphincter neuropathy & $5(14)$ \\
Defect and neuropathy & $20(57)$ \\
\hline
\end{tabular}

TABLE IV Sphincter defects in relation to episiotomy or perineal tear

\begin{tabular}{llll}
\hline & $E A S$ & $I A S$ & $E A S+I A S$ \\
\hline Perineal tear $(\mathrm{n}=7)$ & $3^{\star}$ & $2 \dagger$ & $2^{\star}$ \\
$\begin{array}{l}\text { Episiotomy }(\mathrm{n}=14) \\
\text { Perineal tear and }\end{array}$ & $7(\mathrm{~A})$ & $2(\mathrm{~A}) ; 2 \dagger$ & $3^{\star}$ \\
episiotomy $(\mathrm{n}=1)$ & - & - & $1^{\star}$ \\
\hline
\end{tabular}

*anterior defect; †posterior defect;

EAS $=$ external anal sphincter; IAS $=$ internal anal sphincter. deep component of this sphincter where the anterior fibres tend to meet lower down the anal canal than posteriorly. All controls were found to have an intact anorectal sphincter complex on endosonography.

\section{ANAL MANOMETRY}

Anal manometry revealed significantly lower anal resting and squeeze pressures in patients compared with controls (maximum resting pressure $76.13 v 111.25 \mathrm{~cm}$ water and maximum squeeze pressure $136.43 v 217.38 \mathrm{~cm}$ water; $\mathrm{p}<0.001)$. Although manometry was able to indicate a defective sphincter complex it was unable to identify the exact site and type of sphincter injury (Table VI).

\section{Discussion}

Anal endosonography has added a new dimension to the investigation of the anal sphincter complex. The endosonic probe causes no more discomfort than routine digital examination of the anus. The technique enables repeated examination of the anal sphincters along the length of the anal canal and permits an accurate assessment of sphincter morphology.

The external anal sphincter complex consists of the subcutaneous component at the anal verge, the superficial component imaged in the mid-canal, and the deep components. The perineal body is an area of muscle fusion between fibres of the external sphincter muscle with those of the transverse perineii. Its proximity to the posterior vaginal wall renders it vulnerable to damage from obstetric trauma.

In this study, most defects of the external and internal sphincters were situated anteriorly and in the mid-anal canal. The anterior half of the sphincter complex is likely to be damaged, especially after childbirth, because the sphincter muscle in this region is thin and any injury to the perineal body is likely to result in damage to the sphincters.

The finding of isolated posterior internal anal sphincter defects after parturition is unusual and requires further prospective evaluation. At this point, we can only put forward theories regarding such a finding. One hypothesis is that

TABLE V Endosonic level of sphincter defect

\begin{tabular}{|c|c|c|}
\hline Anal canal & $\begin{array}{l}\text { External sphincter } \\
(n=31)\end{array}$ & $\begin{array}{l}\text { Internal sphincter } \\
(n=21)\end{array}$ \\
\hline Upper & 0 & 4 \\
\hline Mid & 18 & 12 \\
\hline Lower & 13 & 5 \\
\hline
\end{tabular}

\begin{tabular}{lrrr}
\hline & Min & Max & Mean $(S D)$ \\
\hline MRP: & & & \\
Cases & 20 & 160 & $76 \cdot 13(31 \cdot 59)$ \\
Controls & 70 & 140 & $111 \cdot 25(20 \cdot 04)$ \\
MSP: & & & \\
$\quad$ Cases & 30 & 294 & $136 \cdot 43(68 \cdot 58)$ \\
Controls & 160 & 300 & $217 \cdot 38(42 \cdot 25)$ \\
\hline
\end{tabular}

$M R P=$ maximum resting pressure $M S P=$ maximum squeeze pressure. 
prolonged bearing down during the second stage of labour causes a raised intrapelvic pressure that results in ischaemia to the pelvic floor and perineum. This is often characterised by blanching of the perineal skin and of anal mucosa that everts itself during this stage of labour. A prolonged ischaemic event of this kind could lead to tissue necrosis or fibrosis, the posterior aspect of the internal anal sphincter being particularly susceptible because its blood supply consists of end arteries, the greatest distribution of which are posterior. ${ }^{11}$ In a muscle like the internal anal sphincter that is constantly under tonic contraction, fractures of such ischaemic areas could result in endosonic defects.

The study also showed that most of the women seen who had a previous history of an episiotomy or a perineal tear had a defective sphincter; this suggests a direct relation between the two. Again, further evaluation of episiotomy as a cause for sphincter defects is required.

Most of the sphincter defects were detected in the mid-anal canal. This has important surgical implications. Whereas the subcutaneous external sphincter defect is easily recognised at operation, deeper defects may be masked by a seemingly intact subcutaneous sphincter. It is likely to be important that the anal sphincters are exposed along the entire length of anal canal so that deeper defects are revealed and appropriate reconstruction performed.

Data from another study have shown that $37 \%$ of primigravida women and a similar proportion of multiparous women with occult sphincter defects either developed a new lesion or had extensions of pre-existing sphincter defects after vaginal delivery. ${ }^{13}$ These findings imply a need for closer monitoring of the anorectal sphincter complex especially after difficult childbirth.

This study has shown that defects of the anal sphincters and sphincter neuropathy are com- monly associated with faecal incontinence after obstetric trauma. Previous studies have shown a greater improvement in continence after a combined repair of the internal and external sphincter compared with a single repair. ${ }^{413}$ Our data support the hypothesis that the internal as well as the external anal sphincter need to be repaired to restore continence in these patients.

We are grateful to Mrs $\mathrm{C}$ Hail for her assistance with photography. K I Deen is supported by the Medical Research Council of Great Britain.

1 Yoshioka K, Keighley MR. Sphincter repair for faecal incontinence. Dis Colon Rectum 1989; 32: 39-42.

2 Parks AG, Swash M, Urich H. Sphincter denervation in anorectal incontinence and rectal prolapse. Gut 1977; 18: 656-65.

3 Keighley MR, Fielding JW. Management of faecal incontinence and results of surgical treatment. Brf Surg 1983; 70: nence and

4 Wexner SD, Marchetti F, Jagelman DG. The role of sphincteroplasty for faecal incontinence re-evaluated: a prospective physiologic and functional review. Dis Colon Rectum 1991 34: 22-30

5 Kimura J. Electrodiagnosis in disease of nerve and muscle principles and practice. Philadelphia: FA Davis 1983: 209303.

6 Burnett SJD, Speakman CTM, Kamm MA, Bartram CI Confirmation of endosonographic detection of external ana sphincter defects by simultaneous electromyographic mapping. Br F Surg 1991; 78: 448-50.

7 Law PJ, Bartram CI. Anal endosonography: technique and normal anatomy. Gastrointest Radiol 1989; 14: 349-53.

8 Law PJ, Kamm MA, Bartram CI. Anal endosonography in the investigation of faecal incontinence. Br $\mathcal{J}$ Surg 1991; 78: investigat

9 Yoshioka K, Keighley MRB. Critical assessment of the quality of continence after post anal repair for faecal incontinence. BrF Surg 1989; 76: 1054-7.

10 Bartolo DCC, Jarratt JA, Read NW. The use of conventional electromyography to assess external sphincter neuropathy in man. F Neurol Neurosurg Psychiatry 1983; 46: 1115-8.

11 Klosterhalfen B, Vogel P, Rixen H, Mittermayer C. Topography of the inferior rectal artery: a possible cause of chronic, primary anal fissure. Dis Colon Rectum 1989; 32 43-52.

12 Sultan AH, Kamm MA, Hudson CN, Bartram CI. Vaginal delivery causes anal sphincter disruption in $37 \%$ of patients (Prospective ultrasound study). A major determinant for development of faecal incontinence [Abstract]. Gastroenterology 1992; 102: A522.

13 Orrom WJ, Miller R, Cornes H, Duthie G, Mortensen NJM Bartolo DCC. Comparison of anterior sphincteroplasty and post anal repair in treatment of idiopathic faecal incontinence. Dis Colon Rectum 1991; 34: 305-10. 